\title{
Aligning Economic and Ecological Priorities: Conflicts, Complementarities, and Regulatory Frictions
}

\author{
Guillermo E. Herrera, Keith S. Evans, and \\ Lynne Y. Lewis
}

\begin{abstract}
Four key policy challenges, framed here as dichotomies, are commonly associated with attempts to improve the use of natural resources in the socioecological commons. These dichotomies present tradeoffs when addressing market failures and in general seem to suggest the need to settle for second-best outcomes rather than first-best outcomes identified in stylized models. Citing examples, we argue that these models, while illustrating these dichotomies, also suggest means for circumventing them, and perhaps provide a degree of optimism about prospective outcomes in socioecological systems.
\end{abstract}

Four problematic dichotomies pervade and complicate the discourse surrounding the management of socioecological systems: conflicts between the regulator and the regulated; between affluence and access; between economic growth and ecological health; and between current and future benefits. While these do not constitute an exhaustive set of impediments to meaningful improvements in the outcome of socioecological systems, they are nonetheless useful in

Dr. Guillermo E. Herrera is professor of economics at Bowdoin College. A bioeconomic modeler, Dr. Herrera strives to better understand the effects of regulations in commercial fisheries and other socioecological systems. Much of his work focuses on the interplay between the ecological attributes of resource systems (spatial structure and dynamics; interactions between species) and the way they are used by human stakeholders. Dr. Keith S. Evans is an assistant professor of marine resource economics in the School of Economics and School of Marine Sciences at the University of Maine. Dr. Evans's work is interested in the linkages between resource management actions and the outcomes experienced in coastal communities, and adaptation by coastal resource users to these policy changes. Dr. Lynne Y. Lewis is the Elmer W. Campbell professor of economics at Bates College. Her research has covered topics including valuation of ecosystem services, water quality trading, water allocation and the impacts of climate change. Recently her work has focused on the economics of small dam removals and restoration of searun fisheries. She co-authors the popular Environmental and Nature Resource Economics textbook with Tom Tietenberg. The 11th edition of this book is forthcoming in 2018. Correspondence: Guillermo Herrera " Department of Economics " Bowdoin College = 9700 College Station, Brunswick, Maine 04011 - 207-725-3496" Email: gherrera@bowdoin.edu

The authors thank the participants at the 2016 NAREA workshop, James Wilson, and anonymous reviewers for their helpful suggestions. This project was supported by the USDA National Institute of Food and Agriculture under Hatch project \#ME021704 and by NSF-EPSCoR Award \#EPS-0904155.

The views expressed are the authors' and do not necessarily represent the policies or views of any sponsoring agencies.

Agricultural and Resource Economics Review 46/2 (August 2017) 186-205

(C) The Author(s) 2017. This is an Open Access article, distributed under the terms of the Creative

Commons Attribution licence (http://creativecommons.org/licenses/by/4.0/), which permits unrestricted re-use, distribution, and reproduction in any medium, provided the original work is 
understanding some prevailing conceptions. We present three models: (a) a conceptual framework that shows possible confluence between economic and ecological policy objectives over time; (b) a stylized fishery model where imperfect compliance obstructs achievement of the first-best outcome; and (c) a model of a fishery in which spatially structured or otherwise ecologically informed regulation can have biological and economic benefits while also alleviating political frictions.

\section{Conflict between the Regulator and the Regulated}

A regulatory body striving to counteract overuse of an extractive commons, or to mitigate the impact of an externality (such as pollution), often finds itself pushing against the inherent equilibrium tendency of the system, i.e., the decentralized invisible hand. In particular, even the best of rules may not be strictly Pareto improving; the incentives of individual actors (e.g., fishermen, polluters) are often misaligned with the objectives of the society perceived by the regulator as its constituency. Rules meant to foster social objectives (such as aggregate dynamic efficiency) in the short- or long term often cause welfare losses for actors in the system. Because these welfare losses can be acute, it is rational for the regulated to try to avert these regulatory changes by casting doubt on the basis of rules, by calling into sharp focus the welfare impacts to which they are being subjected (i.e., generating political or popular support for their positions), or by simply declining to abide by the rules. All of these responses add friction to the regulatory process, necessitating reductions in the intensity of regulatory intervention, and in some cases qualitatively precluding regulatory approaches that would benefit society as a whole.

\section{Affluence versus Access}

Tradeoffs exist between aggregate affluence - what economists generally call efficiency - and access. Many regulatory and policy initiatives intended to increase the overall net benefits emerging from a socioecological system over time - what is commonly referred to as dynamic efficiency - are predicated on curtailing access to the system. For example, privatization (or rationalization) of a recreational amenity may result in pricing that precludes traditional users from enjoying recreational flows; in the case of fisheries that are deemed overcapitalized, the logical policy response is to remove participants, along with their capital, from the system.

These phenomena give rise to a political problem of a different kind than the acute welfare effects alluded to above, although there is some overlap between the two. The problem with curtailing access is that many see their participation in an industry or activity as a cultural entitlement - something that defines 
them, and that they have inherited from their predecessors. The utility derived from participation per se is a distinct though complementary component of these stakeholders' utility function. Therefore, regulatory approaches that emphasize an aggregate greater good, but for a smaller number, are vulnerable to criticism for deprivation of access; this opposition can be a critical impediment to enacting regulatory change, especially because those deprived of access are often charismatic and have strong ties to the community.

\section{Economic prosperity versus ecological health.}

In many policy contexts, the objective of economic growth, or prosperity, is considered orthogonal to, or at least disjoint from, the objective of environmental recovery or conservation. Examples of this juxtaposition include the "Owls vs. jobs" debate in the Pacific Northwest (New York Times 2007), Sarah Palin's rallying cry of "Drill, Baby, Drill" as symbolic of the conflict between petrochemical-fueled economic growth and concern about environmental risks, and climate change skepticism as the response of threatened industries to measures designed to protect long-term global environmental health. While economic and ecological priorities have some standing in the formation of policy, there are several reasons why there is commonly a bias in favor of economic objectives when the two are viewed as separate and conflicting. First, the pecuniary, dollarized benefits emerging from market interactions and industrial activity are concrete, relatively certain, and easily aggregated into what may be called a bottom line. Ecological benefits, by contrast, are typified by scientific uncertainty and are also multidimensional, so they are difficult to quantify and difficult to distill down into a form that is easily digested by the policy process. In addition, the stakeholders of economic benefits are often proximal in space and time to the policy decision, whereas ecological benefits are more diffuse spatially and often accrue over longer timescales; beneficiaries of these flows may be disenfranchised entirely or at least disadvantaged by the imposition of a significant discount rate to future benefits. In short, when the moral imperative of ecological or environmental protection is held up against financial opportunity costs, the latter often overshadows the former. Even absent this bias, the prevailing view that these two important dimensions of value are fundamentally at odds leads to intransigent conflict within the political process - a counterproductive politicization of policymaking. Any mitigation of this adversarial perception can make management of socioecological systems more harmonious, more expedient, and generally more effective.

\section{Present versus future benefits}

A social planner, or regulator, is tasked with being far-sighted, enhancing social welfare over a potentially long time horizon. However, because policies 
consistent with this objective often involve sacrifices by current stakeholders to improve the lot of future stakeholders, there is an inherent resistance to such measures in the policy arena. In an electoral context, the beneficiaries of such intertemporally structured policies are often not able to vote for or against an initiative or a politician who supports an initiative; indeed, these stakeholders may not even exist yet. Beyond the technical issues of discounting and uncertainty associated with future benefits, self-interested political incentives are often sufficient to avert regulatory change that might otherwise be deemed dynamically efficient. For example, fishermen often oppose reducing total allowable catch allocations, even when evidence suggests sizable future gains for the fishery.

These four dichotomies, often acting in concert, can present significant impediments to the implementation of meaningful changes in the management of socioecological systems. In the analysis that follows, we use conceptual models to refute these dichotomies. That is, we will point out ways different parties' incentives can be aligned to reduce the tendency toward market failure, and ways complementarities between objectives, rather than conflicts, can be achieved.

\section{Conceptual model: Economic value versus ecological health}

Our interaction with environmental systems is influenced by the economic values they provide under alternative uses. The economic value emerging from the environment and natural resource system can take many forms, some harder to quantify than others. Revenues generated by an industry operating along a river, e.g., from a hydro generator or fish processing facility, are easy to quantify; the values embodied in real estate are less so, and the diffuse, nonmarket values from angling, boating, etc., are even more difficult to quantify. Historical variation in economic values across alternative uses of these systems has favored industrial development to promote economic prosperity. As preferences have changed over time, the historical focus on market/industrial values has diminished, and society has increasingly acknowledged values associated with ecosystem services. These shifts will continue to affect our definition of optimality in the use of socioecological systems.

Figure 1 illustrates a hypothetical time path of economic prosperity and ecosystem health from pre-industrial through modern times. The timescale may vary, but this picture is very similar for two of the once-great industries of the state of Maine, USA manufacturing based on rivers for power, transport, and waste disposal; and the groundfish industry, with Atlantic cod (Gadus morhua) as its key target. One should recognize, however, that the patterns depicted in the figure are not unique to Maine and exist in many terrestrial and marine settings around the globe (e.g., rainforest deforestation in Latin America to generate agricultural land; collapse of the Peruvian anchoveta fishery in 1972). 


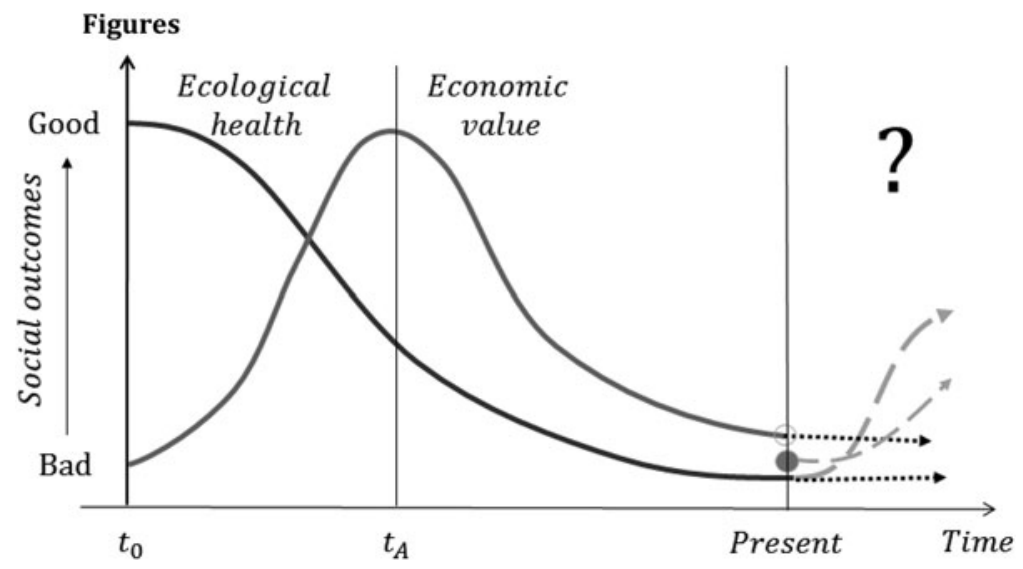

Figure 1. Hypothetical time path. Economic value and ecological health from pre-industrial through modern times. From $t_{0}$ to $t_{A}$ depicts the tradeoff between economic growth and ecological health. From $t_{A}$ to present shows diminished economic value in an ecologically degraded system. Black dotted lines represent the trend toward a stagnant/depressed local economy achieved through degradation of the ecosystem. Gray dashed lines recognize potential win-win scenarios associated with costly investments in improvements in ecological health

In our example (Figure 1), the ecosystem started out in a healthy state, but ripe for exploitation (date $t_{0}$ ). Industry, with extractive use and pollution, profited as technology, population, and markets developed. Progress genuine given the priorities and information available to decision-makers at the time - came at the expense of ecological health, which can be defined in many ways, such as fishery exploitation and industrial use of waterways. The ecosystem declined as industrial wealth was generated, both from extraction from the natural system as well as from the pollution externalities of production (Figure 1, movement from $t_{0}$ to $t_{A}$ ). In many cases, despite economic returns, ecosystem health remained low, with rivers polluted and dammed, and fish stocks under pressure and/or pushed to the wrong side of tipping points.

Not all of this economic progress has, or can be, sustained (Figure 1, movement from $t_{A}$ to present). For example, textile and paper mills in Maine, USA have shut down for a number of reasons, AND fish stocks have been depleted, echoing a global theme of serial depletion/fishing down the food web/value chain (Pauly et al. 1998, Essington, Beaudreau, and Wiedenmann. 2006, Sethi, Branch, and Watson, 2010). Over time, this leaves communities, and often the broader society with a worst-case scenario - a stagnant/ depressed local economy achieved through degradation of the ecosystem. In 
some cases, however, investments in ecosystem health, while initially costly, have moved us to a different path, whereby economic value generated from the natural system is positively tied with ecosystem health. In the following section, we utilize a 'ball-in-basin' model to describe potential impediments to moving toward these win-win scenarios in an ecological-socioeconomic landscape.

\section{A ball-in-basin model of the policy landscape}

The policy landscape captures anticipated tradeoffs facing policy-makers under alternative management options, given the current regulatory framework. Anticipated tradeoffs are complicated by uncertainty about size and location of economic returns and the often multi-dimensional nature of the problem. For example, the environmental policy landscape associated with managing a bay may require compromises between market returns from an active commercial fishery and working waterfront, the nonmarket amenity values related to recreation use and natural viewscapes, and localized water quality. In the following, consider a simplified representation of this policy landscape in the absence of uncertainty, instead focusing on two stylized characteristics: ecological health and economic value. While an abstraction from reality, this simplification offers some useful insight; we will revisit the impacts of uncertainty later.

We can depict this two-dimensional landscape through the ball-in-basin model (Holling 1973, Walker and Salt 2006). In this model, basins represent points of attraction in the policy landscape - providing larger economic returns for society. The historical trajectory (depicted in Figure 1), from an ecologically healthy but relatively impoverished starting point, toward a wealthier but ecologically degraded state, represents the classic dichotomy between economic affluence and ecosystem health. Figure 2(a) provides a depiction of this historical compromise - degrading the ecological system to generate economic returns - as we move toward the industrial basin' labeled $A$; note that basin A corresponds to the system at time $t_{\mathrm{A}}$ in Figure 1.

Eventually, however, both the ecological and economic systems may settle into a degraded steady state (as depicted in Figure 1, movement from $t_{A}$ to present). This suggests that the policy landscape can change over time: the depth of the industrial basin can decrease due to endogenous and exogenous factors. For example, dynamic preferences, shifting economic value toward improved ecological conditions, or technological progress altering society's extractive needs and the production-based pollution externalities, may lead to accretion within the industrial basin while forming new, potentially deeper, basins associated with a higher level of ecological health. Figure $2 \mathrm{~b}$ illustrates possible changes to the policy landscape. Accretion in the industrial basin (a change in the policy landscape from line (1) to line (3)) reduces the economic returns from remaining at A, making it less desirable. Simultaneously, a new basin has emerged in which economic affluence is associated with a 
(a)

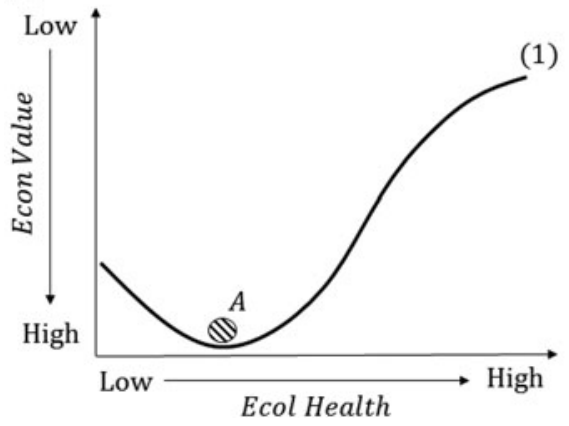

(b)

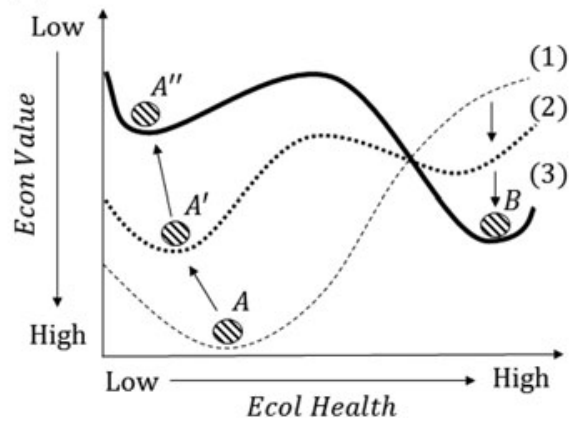

Figure 2. Ball-in-basin model. Panel (a): Static view of the policy landscape where ecological health and economic value are sharp substitutes. Panel (b): Dynamic view of the policy landscape where changes in preferences and/or technology alter the depth and location of basins, creating more complex interactions between economic value and ecological health. Note that economic benefit (value) increases as the system moves down in the vertical dimension

healthier ecosystem. We will call this the ecological basin, labeled $B$ in the figure. The ecological basin could represent a restored fishery, nature-based tourism, an ecosystem-based management cognizant of interconnectedness. This new basin might eventually be deeper (as depicted in the figure) - a new optimum optimorum - but it cannot be reached through incremental movements, due to the gravitational pull of the industrial basin.

The shape of the landscape (i.e., the hump) between the basins, represents the frictions associated with moving from one local optimum to another, and is important when considering how to move across the policy landscape to ostensibly better basins. The left-hand side of the hump captures the gravitational pull, or inertia, of the historical industrial basin. Movements away from this basin, e.g., toward the ecological basin in Figure 2, are costly, both financially (e.g., investment in the removal of dams from river systems) and politically (e.g., legal actions associated with a redistribution of winners and losers); political objections can of course translate in some cases into economic (i.e., dollarized) costs. With multiple groups of stakeholders involved in the use and management of environmental and natural resource systems, regulators and political officials may act so as to avoid legal conflicts even if the ecological investments correspond with an expected increase in long run aggregate economic returns; a behavior consistent with Pope's (1983) management objective of minimum sustainable whinge. Political tensions may be exacerbated if these groups have different preferred management objectives, e.g., social, economic, or environmental objectives (Hilborn 2007). In order to move toward the ecological basin, society must 
overcome these transactions costs. The right-hand side of the hump captures positive feedback effects, pulling us toward the new ecological basin, once a critical mass of stakeholders is achieved. That is, changes in the composition of stakeholders interested in the new basin, e.g., the migration of amenity seekers into an area, can make subsequent improvements more politically tenable. The change in stakeholder composition may encourage investments in infrastructure, improving economic returns under the ecological basin (e.g., tourism and recreation), or it may simply become evident to those involved that the new basin is superior to the initial one.

One limitation of the ball-in-basin model described above is its unidimensional characterization of ecological health. For example, how does the case where a dam provides low-carbon electricity but disrupts a riparian ecosystem compare to that where the river flows naturally but natural gas or coal is used to generate power? Similarly, economic value is multidimensional; it includes industrial profits but also recreational and aesthetic flows. Dams generate industrial wealth by providing low-cost and low-carbon electricity, but also alter the river system's viewscape and its recreational use. How does a dammed river compare to an undammed one in the economic dimension? Different human activities generate very different types (and sizes) of externalities, and alternative investments in (or degradations of) ecological health give rise to winners and losers. Insights of the ball-in-basin model can be extended to consider more complicated multidimensional tradeoffs.

Figure 3 depicts a three-dimensional policy landscape, drawn as a contour map. Suppose that this landscape corresponds with alternative river uses and/or restoration activities, which in turn imply different levels of ecosystem services (increasing along the vertical axis) and carbon emissions (increasing along the horizontal axis). The five basins in the figure, labeled A through E, capture the economic returns, in descending order (with basin A capturing the greatest economic value), of alternative trajectories of multidimensional ecological health. For example, dam removal may increase carbon emission (moving the system to the right) but improve sediment transport and fish passage (moving the system upward). Imagine that basin E represents the long-run industrial basin, corresponding with reduced riparian ecosystem services but lower carbon emissions (consistent with hydropower generation). As in the twodimensional model, movement between basins is costly. The white space between basins represents the policy humps from the previous model, but with an added complication. Not only is the movement to basin A costly for society (as it involves financial and political expenditures), but it also requires society to trade between different types of ecological benefits such as reduced carbon emissions and increased ecosystem services.

\section{Regulatory approaches}

The shape of the policy landscape can be changed in different ways. Over time, the depth of different valleys (or local equilibria) can increase or decrease as a result 


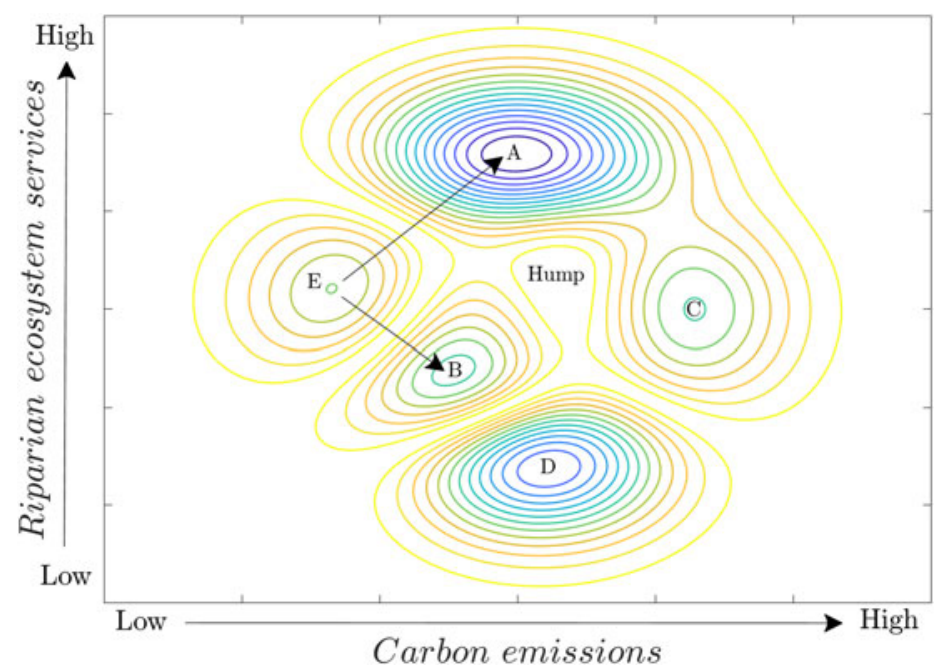

Figure 3. Ball-in-basin contour map. The basins are labeled $A$ through $E$ in descending order of economic value. Humps exist between policy basins, making movement between basins, for example, from basin $E$ to basin $A$, costly

of changing market conditions, technologies, or social priorities, so our definition of what a better equilibrium is might shift over time. The inertia (or resilience) of these local equilibria, as depicted by the shape of the hump between basins discussed above, can also change over time. How do we move through the policy landscape to recover or improve economic prosperity? That is, what are the regulatory approaches to improving outcomes in an integrated ecologicaleconomic or socio-ecological' landscape? It seems that there are two potential approaches: First, we can strive to deepen the industrial basin, potentially coupled with modest improvements in its ecological health, as shown in Figure 4a. Second, we could reduce the policy hump between basins, thereby smoothing the transition to the ecological basin (Figure 4b).

Deepening the industrial basin, and potentially improving its associated ecological health, can be achieved incrementally through a series of quantitative changes in regulations, e.g., tightening or loosening of extraction limits or allowable technologies. This may require creative thinking about interactions with our environmental systems and a deeper recognition of linkages within the coupled natural and human systems. These adjustments may generate costs that reduce the short-run economic value of the industrial basin, but, over time, encourage movement to the new basin with improved economic value and ecological health.

Alternatively, regulatory efforts can focus on reducing the frictions associated with moving from one basin to another, i.e., the size of the policy hump. For 

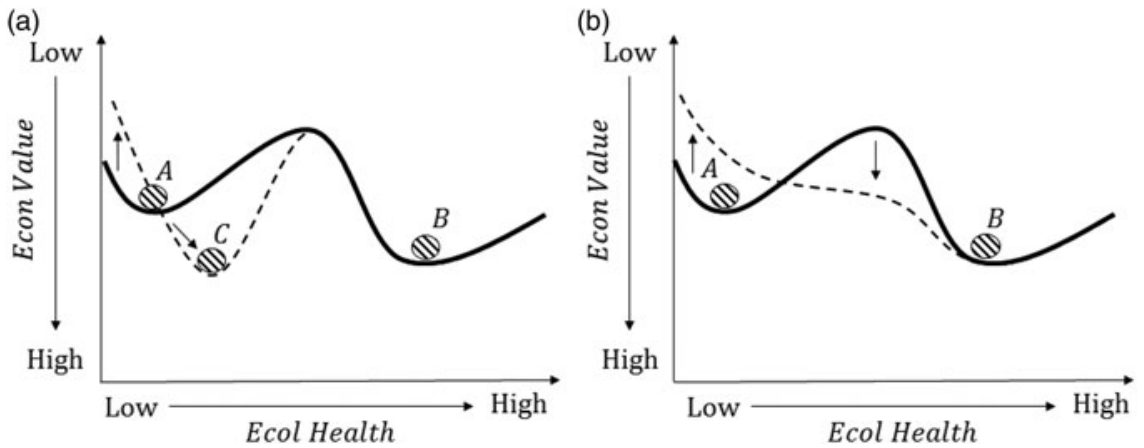

Figure 4. Regulatory efforts in the ball-in-basin model. Panel (a) depicts efforts to marginally improve the industrial basin, increasing economic value and ecological health at the cost of short-run economic losses. Panel (b) depicts efforts to reduce the frictions involved in moving between basins, easing the transition to the ecological basin. Economic value increases in the downward direction

example, regulators can facilitate the translation of the scientific findings into a form that is readily accessible not only to policy-makers, but also to stakeholders who are affected in the short term and are skeptical of the benefits. Knapp and Rubino (2016) note that incomplete information about such shortrun/long-run tradeoffs has hindered the development of marine aquaculture in the United States. In addition to improving communication, addressing distributional concerns could mollify tensions over transitions, acknowledging that any meaningful change in how we interact with the ecological system is unlikely to be Pareto-improving, and explicitly including measures to address the distributional effects that are considered desirable in aggregate.

Empirical evidence suggests that the unidirectional transfer of knowledge from scientists to the broader community is insufficient for generating resilient systems (Roux 2006, Adomssent and Godemann 2011), and academics are often accused of ineffectual translation of their findings into policy-relevant terms (Olson 2009). Instead, this process should be multidirectional, involving stakeholders (e.g., fishermen, landowners) in the regulatory/governance process, to enhance credibility and gain access to better, spatially explicit information.

Better information can also serve to reduce uncertainty over the depth and location of basins in the policy landscape - information about the existence and nature of different outcomes, equilibria, and valleys. This is essentially the role of many benefit-cost analyses. But the main challenge is to quantify, or otherwise make evident to policy-makers and the body politic, the extent to which categorically different outcomes are likely to be better. Ecological analysis can inform us how to better characterize ecological health and natural and resource economists can - through non-market analyses, bioeconomic 
models of complex systems, etc. - present the anthropocentric benefits in terms that can be more readily compared using conventional metrics of economic well-being. These metrics are expressed commonly in dollars but can also take the form of employment, health outcomes, etc.

Another approach to facilitating transitions lies in the trajectory of the transition in the time dimension. In particular, it has been suggested that political feasibility can be enhance through the use of policy ramps, i.e., a gradual phasing in of regulations so as to allow affected firms and individuals more time to adjust and increase their elasticity, decreasing the cost of adjustment. In addition, transitional assistance such as job training and placement services in the case of sectoral shifts, and vessel buybacks in the case of fishery regulations, can be helpful.

Finally, we can ease transitions by designing regulations that are harmonious with the ecology of the system, or that in other ways make human use/access compatible with other regulatory goals. This may require that we scale the resolution of management to match the scale of ecological heterogeneity, and explicitly recognize ecological linkages (ecosystem-based management). For example, Steneck and Wilson (2010), suggest that managers' reliance on a single scale for management of a fish stock with patchy metapopulations encourages "roving bandit" behavior by mobile fishing fleets, leading to serial depletion of the stock. If we understand the system better and can regulate accordingly, then (i) regulations will be less onerous, and (ii) participants will buy into regulations more readily, reducing regulatory frictions.

\section{Win-win trajectories: Dams and river restorations}

Figures 1-4 illustrate possible trajectories of the ecological and economic systems in a conceptual framework. Real-world examples abound. Historically, the jobs versus environment tradeoff has been represented as always negatively correlated. More recent cases show positive correlation between economic prosperity and ecological health, with recognition of the economic value of goods and services not typically traded in the marketplace.

This section briefly describes three examples of win-win scenarios related to dams and river restorations, two inside and one outside of Maine, USA. All of these scenarios represent cases of efforts to restore diadromous (sea-run fish) to their native rivers, bringing both freshwater and inshore benefits with them. Trajectories of the upswings in ecological and economic benefits turn out to depend heavily on local conditions and consensus among the stakeholders involved.

\section{Dams and Dam Removal}

Dams are an example of human ingenuity, of converting potential/kinetic energy into a usable form. The decision to build a dam is usually made because the perceived (or measured) benefits are greater than the perceived 
costs. Thousands of small dams were built to power individual mills, with decentralized utilitarian purpose. In the West, large dams provide hydropower, water supply, flatwater recreation, and flood control with little regard to the loss of habitat, and the ecosystem and recreation benefits of free-flowing rivers. Industrial benefits of dams on rivers have declined, largely due to exogenous shocks including competition from other countries and changes in technology that remove the need for water-powered operation. There has been a sharp increase in the appreciation of the anthropocentric benefits of undisturbed/restored riparian systems, making for a new valley at a higher level of ecological health. These benefits include recreational fishing, recreational boating, swimming, wildlife viewing, and benefits to riparian property owners.

Maine is home to the first federally licensed dam to be removed for purposes of anadromous (sea-run) fisheries restoration and boasts the largest river restoration project east of the Mississippi River (www.penobscotriver.org/). The Edwards Dam in Augusta, Maine was removed in 1999, setting a precedent for the inclusion of nonmarket economic values in relicensing decisions by the Federal Energy and Regulatory Commission (FERC). Lewis, Bohlen and Wilson (2008) found that removal of the dam also removed the penalty (negative impact on price) for homes near the dam site. Homes upstream at the next dam site also experienced a decline in this penalty, albeit not as large. Expectations about future dam removal and fish passage likely influenced this change. Indeed, in 2008, the Fort Halifax Dam was removed, and innovative fish lifts were built and installed at the Lockwood and Benton Falls Dams. Since this time, thousands of anadromous fish have successfully migrated to their historic spawning grounds. Robbins and Lewis (2008) also found positive (and sizable) potential economic impacts for recreational anglers.

\section{Penobscot River Restoration Project}

The Penobscot River Restoration Project, on the largest river in Maine, is one of the largest riparian restoration projects in the country and by many economic and ecological measures an example of a win-win in the ecological-economic landscape we have depicted above.

At the time the Penobscot River Restoration Project was signed, there were 20 hydropower dams operating on the river and hundreds of small nonhydropower dams. The agreement between the power company that owned the dams, the Penobscot Indian Nation, Federal and State governments, and a coalition of environmental groups, has resulted in the removal of the two lowermost dams on the river, fish passage built on the third, and an innovative bypass built around the fourth dam in the river (penobscotriver.org). This has resulted in the opening of approximately 1,000 migratory miles for endangered Atlantic salmon and 500 miles for sea-run fish such as the Atlantic shad and American sturgeon. Simultaneously, hydropower was enhanced on several tributary 
dams, thus maintaining approximately 100 percent of hydropower production on the river. Ecological potential of the river was enhanced without sacrificing economic productivity. New developments such as a paddler's festival and renewal of waterfront parks bring economic benefits to the region. While too early to measure the slope of the upswings, these win-win arrangements offer the most potential for both ecological and economic gains.

\section{Klamath River Restoration}

Successful dam removal and restoration efforts in Maine have set a precedent for other locations considering dam removal. For example, in April of 2016 year, the Governors of Oregon and California, along with PacifiCorp, owner of four large hydroelectric dams, signed a series of agreements - the Klamath Hydroelectric Settlement Agreement, the Klamath Basin Restoration Agreement, and the Upper Klamath Basin Comprehensive Agreement - with the goal of restoring salmon habitat and habitat for other threatened species along the Klamath River. The agreement creates the Klamath River Renewal Corporation, a nonprofit organization to oversee the decommissioning process, similar to the role of the Penobscot River Restoration Trust. The negotiations included tribal farming and fishing interests and now needs Congressional approval. The above-named agreements are the result of years of negotiations and tensions between tribal, agricultural, and fishing interests. Removal of these four dams will restore habitat to what was the third largest salmon run in the United States.

Restoring salmon fisheries offers the potential for large economic and ecological benefits, i.e., for the steep upswing scenario shown in Figure 1. These dams provided important economic stability to this region in the early 20th century, but more holistic benefit-cost analysis supports removal for fisheries restoration. The public utility commissions of California and of Oregon support this decision.

\section{Reducing regulatory frictions in commercial fisheries}

Separate from dams, conflicts between economic and ecological objectives clearly manifest themselves in extractive natural resource industries. Even when managed in a dynamically efficient manner, resource owners'/ managers' inability the inability to capture nonextractive values often causes extractive net revenues to be privileged over the system's ecological health. Forests have, until fairly recently, harvested with an eye on profits, less so with regard to the recreational amenities and ecological function; and commercial capture fisheries have traditionally focused on their target species without much regard for the ecological impacts caused by the removal of these species.

Commercial fisheries are an especially compelling case of the ball-in-basin model we describe in the conceptual model above: the equilibrium basin in 
an overexploited resource (fishery) has low ecological health and economic benefits that have worsened over time. It is often evident that there exists a basin that is better in both regards: harvesters could make more money by doing less work in what could be called a Pareto-improving reduction in fishing effort by all concerned, and this improvement would result directly from letting the stock recover to a higher level where it is more productive. Despite the superiority of the new basin, along both economic and ecological dimensions, it can be difficult to move from the depleted basin to a more desirable basin because of real or perceived hardship experienced by participants in the short term, because of objections to loss of access (distinct from profitability) and due to skepticism regarding the scientific basis for regulations intended to facilitate the shift between basins.

\section{Bioeconomics and regulatory frictions}

Here we present a simple extension of a common bioeconomic model to include regulatory frictions, and discuss means for mitigating these. While ecologically and economically stylized, the Gordon-Schaefer fishery model is ubiquitous in the resource management literature and serves as a conceptual tool that illustrates the tendencies of open-access natural resources to exhibit overcapitalization, resource depletion, and dissipation of economic rents. In Figure 5(a) below, decentralized entry increases the level of the extractive input (effort, ' $E$ ') to the open-access level $E_{O A}$, where sustained total revenues are exactly equal to sustained costs of effort (so that net benefits are equal to zero). This level of effort, or capital, is significantly higher than that ( $\left.\mathrm{E}_{\mathrm{MEY}}\right)$ in the efficient maximum economic yield (MEY) case. Panel 5(b) represents the same phenomenon in a different dimensionality ( $E$ vs. \$/E): individual harvesters respond to average revenue (AR) as their benefit of entering, while the social marginal benefit of their entry is marginal revenue (MR).

Some (e.g., Ostrom 1990) argue that the participants might be able to mitigate this rent-dissipation via locally enforced contracts, although the prognosis for such solutions deteriorates in systems with large numbers of stakeholders with heterogeneous objectives. In cases where internal resolution is not feasible, an external actor, i.e., a regulator, intervenes in the system to counteract its inefficient tendencies.

The basic Gordon-Schaefer model assumes that costless or frictionless regulation can move the system to its optimal MEY outcome through using a range of policies such as input taxes, a moratorium to allow stock recovery followed by restrictions on withdrawals, and tradable quota systems. While these policy instruments differ in subtle ways, all of them ultimately require a reduction in the level of effort, which can be seen as a proxy for access to the industry. When access is curtailed in the name of economic efficiency, this usually implies acute short-run welfare impacts on participants with stranded, nonmalleable physical and human capital. Reduction of access is also seen as an affront to those with nonpecuniary attachments to 
(a)

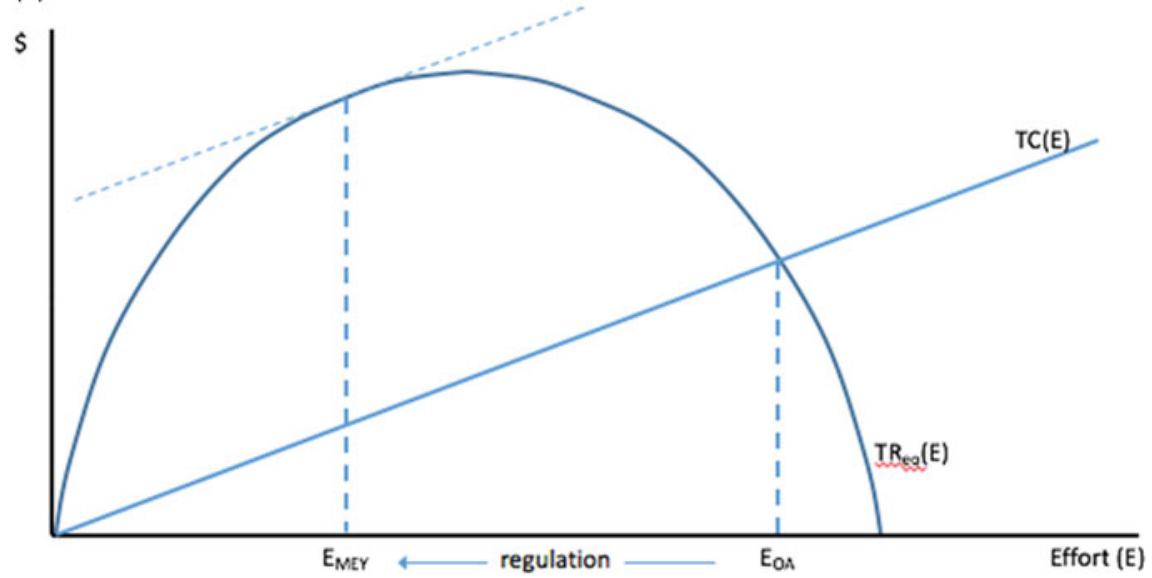

(b)

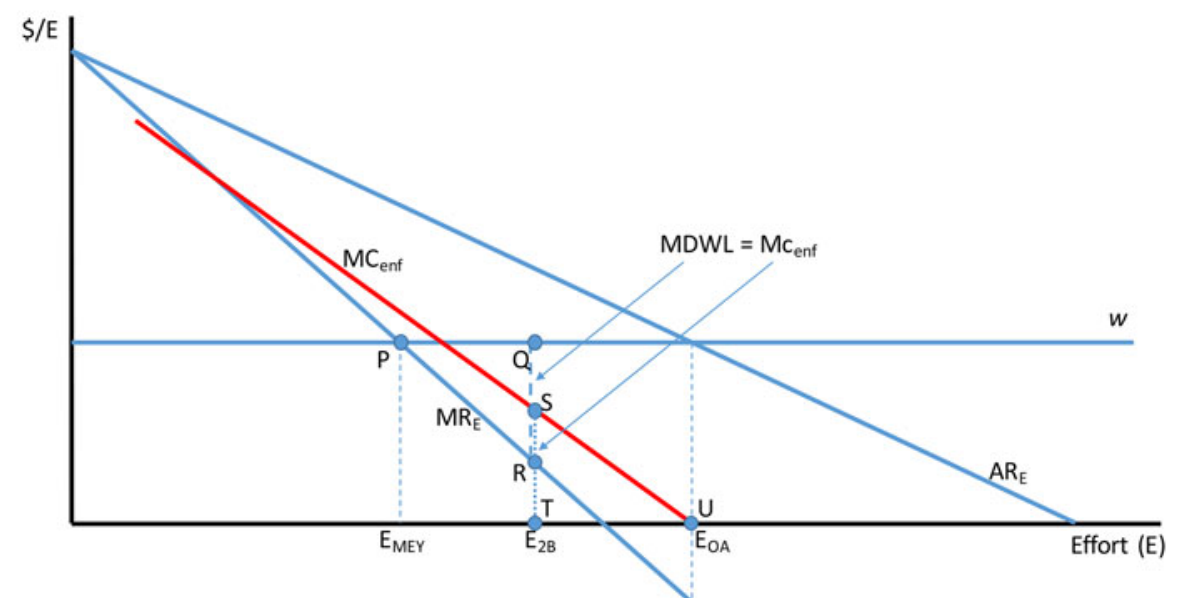

Figure 5. Outcomes in the Gordon-Schaefer fishery model. Panel (a) shows the standard comparison of open-access $(\mathrm{OA})$ and maximum economic yield outcomes, and assumes frictionless regulation. Panel (b) includes marginal enforcement costs embodied in the red $\mathrm{MC}_{\mathrm{enf}}$, which imply a second-best regulatory outcome exhibiting positive efficiency losses

participation in the industry, i.e., depriving them of what they see as their heritage; fishing is a way of life for which participants often have value that complements, or even transcends, economic gains. These welfare impacts hinder the resolution of inefficient outcomes, giving rise to either political objections or noncompliance with regulations. 
In the Gulf of Maine, for example, there is a longstanding adversarial relationship between regulators and fishermen. The federal government, largely under the auspices of the National Marine Fisheries Service, has responded to overuse by imposing restrictions on fishing activity, but the nature of these regulations - sudden, severe, and fairly undifferentiated across the system - has led to both short-term loss of welfare on the part of harvesters, observations by fishermen of stock abundance that do not correspond to the regulators' characterization, and subsequent loss of credibility on the part of the regulatory agency. The 2002 Trawlgate episode, in which federal survey trawlers were perceived as fishing with improperly deployed gear (Benjamin 2002), is a colorful example of the challenges of regulated systems. Though the error was later shown not to have had significant impacts, it amplified a pre-existing credibility problem in the Gulf of Maine system. Efforts to regulate systems toward their MEY levels also face formal obstacles, e.g., under the rubric of National Standard 8 of the Magnuson-Stevens Fishery Conservation and Management Act, or other objections to acute short-term welfare losses to charismatic and vocal stakeholders.

Figure $5 \mathrm{~b}$ shows the impact of such frictions on the regulatory process. Either political objections or the costs of enforcing regulated reductions in $\mathrm{E}$ can be embodied in the Marginal cost of enforcement curve, $\mathrm{MC}_{\text {enf }}(\mathrm{E})$, an increasing function of $\Delta \mathrm{E}=\mathrm{E}_{\mathrm{OA}}-\mathrm{E}$, the reduction in effort from its open-access level. The introduction of $\mathrm{MC}_{\text {enf }}$ suggests a second-best regulated outcome, $\mathrm{E}_{2 \mathrm{~B}}$, such that the marginal deadweight loss of effort is balanced by the marginal enforcement costs associated with achieving a reduction in effort: MDWL $(E)=M_{\text {enf }}(E)$, where $\operatorname{MDWL}(E)=M C(E)-M R(E)$. In such a system, given the exigencies of regulatory friction, it is no longer feasible/optimal to drive effort all the way down to $\mathrm{E}_{\mathrm{MEY}}$.

The second-best outcome dictated by costly enforcement exhibits two forms of social efficiency loss: some of the rent per se from the harvesting operation (area PQR) remain dissipated, and explicit enforcement costs (area STU) must be incurred.

Enforcement costs lead to an inherently suboptimal level of effort in this simple regulated system, but some regulatory innovations can specifically target the enforcement cost curve and mitigate its negative impacts. Regulations can be phased in slowly, through policy ramps (Nordhaus 2007), thus ameliorating the short-run welfare effects of effort reductions. The government can provide assistance with job retraining or retrofitting vessels to address the nonmalleability of capital. Aquaculture can serve as a substitute employment opportunity that allows participants to retain some of their cultural attachment to the ocean. Some forms of transferable effort or harvest quotas can mitigate enforcement costs, if the initial allocation of quotas is used to soften the welfare impacts associated with reduced total effort; they can also provide some participants with a 'graceful exit'. In addition, participants can be actively enfranchised, involved in the regulatory 
process and the scientific processes underlying regulation, to increase their confidence in the validity of regulations as well as their confidence that their interest is being considered.

Ecologically informed regulations provide a qualitatively different paradigm for mitigating enforcement costs that arise from reduced access, and for facilitating the transition to new equilibria that are preferable both economically and ecologically. This result has been demonstrated in a spatial extension of the Gordon-Schaefer model (Neubert and Herrera 2008), as described below. The intuition that arises from these models in the spatial dimension can be extrapolated to a range of regulatory approaches that appropriately account for biological heterogeneity in exploited systems. We summarize that modeling framework here, as its results correspond closely to the ball-in-basin framework and the mitigation of regulatory frictions.

Neubert and Herrera (2007) assume a finite habitat on which stock grows logistically at each point in space. The spatial dynamics of the resource are modeled with a simple diffusion process. Finally, the habitat is assumed to have hostile boundaries; abundance is forced to zero at the ends of the habitat.

Three key outcomes, shown as distributions of effort across the spatial dimension in Figure 6, can be compared using this model in a way that closely parallels the results of the nonspatial model shown in Figure 5 above. (i) $\mathrm{E}_{\mathrm{OA}}(\mathrm{x})$ shows effort distribution across space associated with open-access, in which entry occurs until rents are dissipated at all locations where fishing takes place; the (ii) ecologically unsophisticated second-best regulation, in which the regulator can control aggregate effort but not its distribution across space, gives rise to $\mathrm{E}_{2 \mathrm{~B}}(\mathrm{x})$. The effort distribution here, though reduced in aggregate magnitude, qualitatively follows the myopic priorities of open-access; and (iii) the first-best, or maximum economic yield case $\mathrm{E}_{\mathrm{MEY}}(\mathrm{x})$, in which the density of effort across the habitat can be fully specified. This spatially structured optimum is solved as an optimal control problem, resulting in an optimized intensity of effort at each location in the habitat.

The fundamental results are illustrated in Table 1: (a) both nonspatial and spatially structured regulation enhance profits; not surprisingly, the spatially regulated effort level, since it can fine-tune intensity of extraction according to the varying in situ value of the stock, is able to achieve more rents; (b) both spatially structured regulation and nonspatial regulation increase equilibrium stock abundance (i.e., ecological health), but again positive outcome is enhanced, and somewhat counterintuitively, spatial regulation can (in a substantial subset of parameter sets) allow for greater participation in the system - not just greater than the case of managed effort without spatial regulation, but greater than the amount of effort that would have been exerted in the open access equilibrium.

Even when effort does not increase (i.e., when $E_{M E Y}<E_{O A}$ ), the reduction in effort required is significantly smaller than in the ecologically naive, or secondbest case: $E_{\mathrm{MEY}}>\mathrm{E}_{2 \mathrm{~B}}$. Thus, even partial refinement of regulations along ecological dimensions can mitigate the necessity to reduce overall effort 


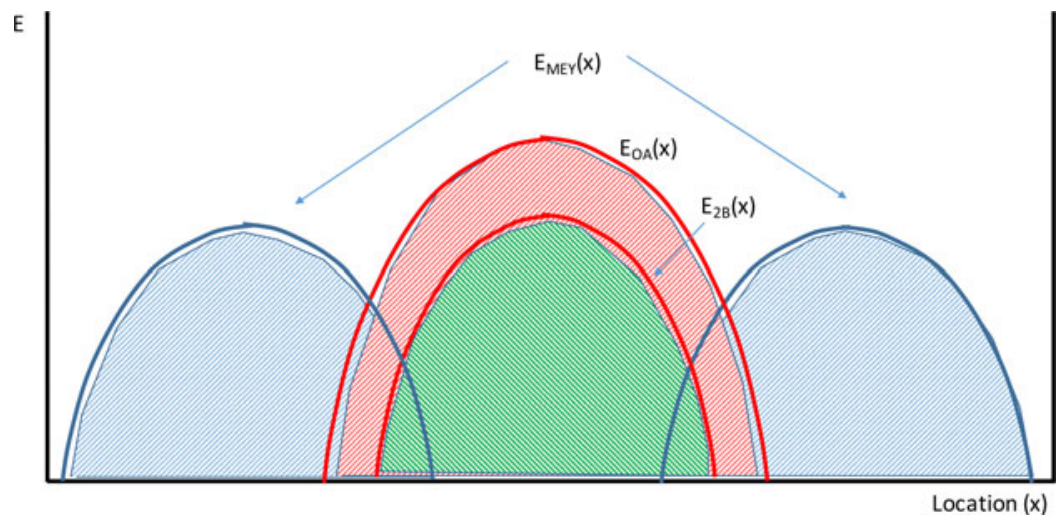

Figure 6. Effort distributions (as per Neubert and Herrera 2007) across the finite spatial habitat under different market structures and regulatory scenarios: $E_{O A}$ emerges from open-access, $E_{2 B}(x)$ from nonspatially regulated open-access, and $\operatorname{EmEy}(x)$ from spatially optimized regulation

(participation), significantly decreasing the cost of transitioning from the overharvested equilibrium to one that is both more profitable and more ecologically robust.

In reality, spatial regulation can be achieved using many different instruments: spatial individual transferable quotas; spatially delineated harvest rights (also known as territorial use rights in fisheries, or TURFs); systems of marine protected areas to simplify the protection of especially valuable units of biomass; and small-scale community-based fisheries management, in which localized communities are given control of segments of the habitat and left to

Table 1. Changes in the key metrics of system performance in the spatially structured fishery under nonspatial and spatially specific regulation: stock abundance $\mathrm{N}_{\text {total }}$, economic net benefits, or rent, NB, and change in total effort or employment $E_{\text {total }}$

\begin{tabular}{lcc}
\hline & Non-spatial & Spatial \\
$\underline{\Delta} \mathrm{N}_{\text {total }}$ & $\uparrow$ & $\uparrow$ \\
$\Delta \mathrm{E}_{\text {total }}$ & $\uparrow$ & $\uparrow$ \\
\hline
\end{tabular}


decide management details on their own. As in the nonspatial case, different instruments will perform better in different contexts; all effective fisheries management must be crafted to suit a particular set of conditions.

The depiction of the spatial dimension, including boundary conditions, spatial ecology of the underlying resource stock, and spatial behavior of the fishing fleet, are all highly stylized in the Neubert and Herrera model. The intent was to introduce the spatial dimension in a simple and tractable way (via the boundary conditions), and see what insights emerged. The results described above would hold true in other instances of ecological heterogeneity: a twopatch model with a simple source-sink dynamic; exogenous variations in habitat quality; a sex-structured population in which one sex has a higher reproductive in situ value; and multispecies systems In all these cases, as long as there is an incentive misalignment associated with the ecological dimension (i.e., harvesters tend to focus on one part of the system due to higher immediate profits, but it is dynamically efficient to focus on another), then effectively resolving that misalignment frees up regulators to allow more effort into the system than with coarse, ecologically naive regulations. The take-home message, therefore, is that basing regulations on good ecology, and being innovative in terms of ecologically oriented aspects of behavior, is politically beneficial. This political-bioeconomic result constitutes a powerful call for interdisciplinary science and policy design as a way of reducing regulatory frictions associated with moving from an unmanaged or poorly managed basin to a preferable one.

\section{Conclusions}

Socioecological systems are highly complex, delivering a wide array of flows to different stakeholders at different points in time. Management of these systems is therefore inherently fraught with uncertainty about what outcomes are possible, and about their relative merits in the economic and ecological dimensions. Natural and social scientific research can help better understand the outcomes, not just what they are in a biogeophysical sense, but who would benefit economically, and how much, from these outcomes in different ways.

Our main focus in this paper, however, is on the process of moving from the current basin to one that is known to be preferable along economic or ecological lines. Even in such cases of sufficient information, there remain significant obstacles to managing, regulating, or otherwise causing the outcome to shift to that better basin. We demonstrate such regulatory frictions in the conceptual models above. Our hope is that these stylized frameworks shed some light on the exigencies of identifying and improving socioecological systems. Genuine interdisciplinary collaboration is required to improve our understanding of the dynamics of these systems, to characterize the human impacts of changes in policies and incentives, and to design regulations that 
mitigate regulatory frictions by responding to underlying biogeophysical dynamics.

\section{References}

Adomssent, M., and Godemann, J., 2011. "Sustainability communication: an integrative approach". In Sustainability Communication: Interdisciplinary Perspectives and Theoretical Foundation, eds. Godemann, J. and G. Michelsen. New York, NY: Springer. pp. 27-37.

Benjamin, M., 2002. “The Real Story behind Trawlgate." Cape Cod Times, 24 Nov. http://www. capecodtimes.com/article/20021124/news01/311249991.

Essington, T.E., A.H. Beaudreau, and J. Wiedenmann, 2006. "Fishing through Marine Food Webs." Proceedings of the National Academy of Sciences 103: 3171-3175.

Holling, C., 1973. "Resilience and Stability of Ecological Systems." Annual Review of Ecology and Systematics 4: 1-23.

Knapp, G. and M.C. Rubino, 2016. "The Political Economics of United States Marine Aquaculture." Reviews in Fisheries Science \& Aquaculture 24(3): 213-229.

Lewis, L., C. Bohlen and S. Wilson. 2008. "Dams, Dam Removal and River Restoration: A Hedonic Property Value Analysis.” Contemporary Economic Policy. 26 (2): 175-186.

Neubert, M.G. and G.E. Herrera, 2008. "Triple Benefits from Spatial Resource management." Theoretical Ecology 1(1): 5-12.

Nordhaus, W., 2007. "Critical Assumptions in the Stern Review on Climate Change." Science 317(5835): 201-202.

Olson, R., 2009. Don't Be Such a Scientist. Island Press.

Pauly, D., V. Christensen, J. Dalsgaard, R. Froese, and F. Torres, 1998. “Fishing Down Marine Food Webs." Science 279(5352): 860-863.

Penobscot River Restoration Trust (Accessed October 2016) "Anadromous Fish." http:// www.penobscotriver.org/content/4027/anadromous-fish

Roux, D.J., K.H. Rogers, H.C. Biggs, P.J. Ashton, and A. Sergeant, 2006. “Bridging the ScienceManagement Divide: Moving from Unidirectional Knowledge Transfer to Knowledge Interfacing and Sharing." Ecology and Society 11(1): 4.

Sethi, S., T. Branch, and R. Watson, 2010. "Global Fishery Development Patterns are Driven by Profit but Not Trophic Level." Proceedings of the National Academy of Sciences of the United States of America 107(27): 12163-12167.

Steneck, R.S. and J.A. Wilson, 2010. "A Fisheries Play in an Ecosystem Theater: Challenges of Managing Ecological and Social Drivers of Marine Fisheries at Multiple Spatial Scales." Bulletin of Marine Science 86(2): 387-411.

Walker, B., and Salt, D., 2006. Resilience Thinking: Sustaining Ecosystems and People in a Changing World. Island Press. 